\title{
Language Development of a Group of Hearing Impaired Children
}

\author{
Al.1DA M. U. LAUBSCHER, M.S. \\ Washington University
}

\section{Introduction}

Recently there has been a great surge of interest and activity in the area of developmental psycholinguistics. This discipline, exemplified by the work of Brown and Bellugi², Ervin (1964), McNeill"1, Menyuk (1963, $1964 \mathrm{a}, 1964 \mathrm{~b})$ and others, has largely arisen because of the theoretical expositions of Chomsky (1957) who provided the formulations concerning the grammatical structures of the English language. This led researchers to apply these principles to the language acquisition of children. The psycholinguists hold that children have an innate capacity to acquire most syntactic rules in the short span of life from one and a half to three and a half years of age. It is a more accurate explanation of language acquisition than the theories of imitation. Evidence that imitation alone does not account for the phenomenon of language acquisition, is the observation that a normal, hearing child at the age of three or four does not produce only sentences which he has heard, but generates his own novel set of sentences. What he acquires is the group of rules that governs the generation of the sentences. He learns a finite set of rules that enable him to produce an infinite set of sentences. This process of indirectly learning the syntactic rules has been called induction of the latent structure by Brown and Bellugi ${ }^{2}$.

\section{Early Grammatical Rules}

The generative grammar model as formulated by Chomsky has been applied in the literature to describe the language acquisition of the child. Brown and Fraser ${ }^{3}$, Braine (1963) and Miller and Ervin (1964) have investigated the earliest two-word combinations of normally developing children and have identified the use of pivot words as the child's first grammatical construction. The two-word combinations' were called sentences. The word combinations were found not to be random, but to follow a pattern, and the words were categorized as belonging either to the open class or to the pivot class: Membership in both pivot and open class is heterogenous from the point of view of being part of speech membership in the adult language. The words in the pivot class emerge later into grammatical classes similar to that of adult grammar.

Brown and Bellugi ${ }^{2}$ have described the development of the nounphrase as a grammatical unit in children's grammar. Building on Brown 
and Bellugi's data, McNeill (1965) proposed that the earliest grammatical constructions are noun phrases and predicate phrases and on occasion, full sentences. The early speech of children reflects the properties of the phrase structure of sentences. It does not reflect the operation of transformational rules; these seem to come into children's grammar at a later stage.

\section{Transformational Development}

A transformational model of structure was used by Menyuk (1963, 1964a and 1964b) to describe children's grammar in the age range from two to seven years to indicate developmental trends. It was found that four-year-old children used a greater number of different transformations per child than three-year-olds. It seems that a four-year-old is less fixated as to the number of different sentence types than a child one year younger. Evidence of the four-year-olds' advanced linguistic competence was seen in their decreased use of simple active-declarative (kernel) sentences as compared with the three-year-olds.

Children mature toward finely differentiated linguistic competence in stages of advancement. The first sentence rules seem to be those relating to phrase structure; these are learned by two to three years. The second stage in learning the rules governing the generation of sentences seems to be that of simple transformations. The final level of maturity would be the mastery of complex transformations.

\section{Morphological Development}

Development of morphophonemic rules, governing pronunciation and relating the syntactic and phonological parts of the grammar, has been investigated; the findings have indicated certain developmental trends. Berko (1966) found the children's usage of noun plurals, verb inflections and possessives indicated a clear developmental trend. The children's performance on verb inflections indicated best performance on the progressive. The past tense of the irregular verb form was never used correctly by the four and five-year-olds and only one child of the sixty. one five to seven-year-olds made use of this construction.

Because the division between regular and irregular verbs is an arbitrary one, rote learning is required in each case. Cazden (1968) found that the irregular forms are often used correctly by the child before he starts to differentiate between the rules. The application of one rule for all forms is often found, for example, "went" and "go-ed" or "walked" and "weared". This overgeneralization is followed eventu. ally by the correct use of the regular and irregular verb. inflections. Cazden (1968), reporting on the development of three verb inflections, found that the present progressive appeared first in the utterances of all three of his subjects; complete mastery was reached between approxjmately twenty. and forty months. The sequence of acquisition of the 
regular past and present indicative was less consistent, relative to age and rate of acquisition.

The studies described above, which utilized a generative model of grammar seem to agree with the hypothesis that the child has incorporated both the generative rules of the grammar and a heuristic component that samples an input sentence, and by a series of successive approximations determines which rules are used to generate a sentence. Also, there appears to be a clear developmental sequence of certain features. If this is an innate capacity that the child brings to the task of acquiring language, it must also exist in the hearing-impaired child. $\mathrm{He}$ should possess a source of hypotheses as rich as a hearing child's, since in both cases hypotheses result from the capacity for language acquisition rather from the language itself. The limitation placed on the hearingimpaired child, however, is the input of the sentence constructions.

\section{Language Acquisition of Hearing-impaired Children}

The main trend of description of the language of deaf children in the past has been based on the rules of traditional grammar. The application of linguistic rules to describe the language of deaf children indicated that deaf children show many features in their language production that some have termed "deafisms": stereotypy, syntactical errors, limited vocabulary and wrong choice of words.

Fries's method of reclassifying parts of speech into four classes and function types, based on their privilege of occurrence in sample sentences, has been a useful procedure in analysing the linguistic performance of hearing-impaired children. Studies utilizing this method have been completed by Simmons (1962), Goda (1964) and McGinitie (1964).

Studying a group of eight to fourteen-year-old deaf and hearing children, Simmons indicated that the deaf exceeded the hearing in the use of Class I words (nouns), Class II words (transitive and intransitive verbs) and determiners. The hearing children used more Class IV words (adverbs, auxiliaries and conjunctions). The two groups used a similar number of Class III words (adjectives and prepositions). The deaf used prepositional groups of place and accompaniment. Comparing the number of different words spoken by each group, the hearing group used a higher type-token ratio than the deaf.

McGinitie (1964), using a sentence completion test, indicated that the deaf children show a nearly uniform retardation in supplying content and function words. These results; are not in complete agreement with the earlier studies by Heider and Heider and Myklebust who indicated that deaf children omit abstract or function words which have no tangible referents. Language of deaf children contains many nouns and verbs which tend to be more concrete.

While hearing impairment seem's to create under-use of some word classes, it results in a tendency to over-use nouns and articles. Hearing impairment interferes with the learning of function words more than 
with the learning of content words. Among the content words, adverbs are found to be an exception. Function words tend to be more redundant than lexical words. Cohen (1967) found that deaf children construct messages with less redundancy than is generally found in the language of their hearing peers.

These investigations indicate that hearing-impaired children are deficient in both specific verbal skills and in general language. When the deaf child's verbalizations are more than rote performances or memorized strings of words, his utterances will reflect a system of formulational rules. These rules can be analysed and the developmental sequence of language can be illustrated. The studies mentioned above described specific structural features in the language of deaf children. A developmental sequence was not indicated.

\section{Goal}

The goal of the present study was to determine whether there are developmental trends of certain language features and formulistic rules in the language of hearing-impaired children. Language development of normal children indicates that certain language features are acquired before others and show improvement in correct usage as a function of age. From the language samples of this group of hearing-impaired children, indications of occurrence of certain features and language rules as well as improvement in correct usage was analysed.

\section{Method}

The language samples of the ten hearing-impaired children in this study represent the age range from five to three years and nine to seven years. The mean hearing level of the subjects, in the better ear, was $76 \mathrm{db}$ I.S.O. The children were all enrolled in the school programme at the Central Institute for the Deaf, St. Louis. Prior to entrance, they were participants in a Parent-Infant programme. Language appropriate to the children's linguistic age levels was used in the school programme. Language was taught through experience; stories which were written following an actual group experience were used. The traditional approach of systematic teaching of structural forms was not followed.

Language was elicited from the children who were instructed to talk about a picture. This was tape-recorded. The procedure followed in analysing samples was directed toward counting the occurrence of certain language features at five age levels. The language samples of each child were analysed with reference to the following features:

(a) The use of single word, two word and three word combinations.

(b) Kernel sentences. According to the generative grammar model, a kernel sentence is any single sentence which is generated without the application of optional transformations. 
(c) Verb tenses and verb inflections. The occurrence of the present tense, past tense (irregular verbs) present and past progressive aspects was counted with reference to which form occurred earliest in the language samples. A comparison of the frequency of occurrence was also made.

(d) The transformations conjunction, conjunction deletion, the auxiliary "have", pronominalization, particle displacement, the comparative 'and passive voice were examined. The age at which the transformations occurred was determined. The usage of sentences, possibly indicating pre-transformational sentence structures, was analysed.

\section{Results}

Verb tenses and inflections. The occurrence of the present tense, the present progressive aspect, the past tense and the past progressive aspect indicated a clear developmental trend. The present tense occurred earliest in the children's language samples. The present progressive aspect and the past tense (irregular verbs) appeared second and third respectively. Although there was not a significant difference in the time of occurrence of the present progressive aspect and the past tense (irregular verbs), there was a significant difference in the frequency of usage of the two forms. The present progressive aspect was used as the dominant form when both occurred in all the language samples. This was especially true for the age range of five to seven years. The past progressive aspect appeared in the language samples at the nine year level. This verb form never appeared before the others.

The present tense was always used in all language samples when verbs were present. As age increased, the present tense was not the main verb form of discourse, and was used less frequently. Other verb forms became the main verb forms of discourse.

A developmental sequence of verb forms appeared to be present, Table I summarizes the occurrence of verb tenses and verb inflections in the language of the subjects. All the language samples, except for two out of thirty-one, indicated the same pattern. The present tense preceded or occurred with the present progressive aspect. The past tense occurred after the present progressive, and the past progressive was the last form to appear. This sequence is representative of the group as a whole. In the two samples in which the developmental sequénce was not reflected, the present and past tenses occurred. Subject III used the past progressive aspect at the age of six years but not in the later samples.

The appearance of the auxiliary "be" with the present progressive, and the inflection /-ing/ were included in the analysis because there appeared to be inconsistencies of correct usage. Omission of either the auxiliary "be" or /-ing/ occurred with the correct usage of the present progressive form. More omissions occurred at ages five, six and seven than at age levels eight and nine. The correct application of "be + ing"

Journal of the South African Logopedic Society, Vol. 17, No. 1: December 1970 
concurrently with an omission of either can be illustrated as follows:

Subject II: "the boy is smiling and the girl smiling, ... the dog is laugh ...

These results appear to be in agreement with the results of Cazden (1968). The present progressive aspect and the present tense were acquired first in the language of his three normal hearing subjects. The auxiliary "be" plus the inflection /-ing/ occurred, with omissions and correct usage at the same time and was not completely mastered at the age of forty-nine months. Berko (1966) reported that at the age of four years the children used the present progressive correctly $90 \%$ of the

Table 1: Occurrence of Verb Tenses and Verb Inflection

Years

\begin{tabular}{|c|c|c|c|c|c|}
\hline Subjects & 5 & 6 & 7 & 8 & 9 \\
\hline I & $\mathbf{N}$ & $\begin{array}{l}\operatorname{Pr} T \\
\operatorname{Pr} \operatorname{Pr} A\end{array}$ & & & \\
\hline II & $+\operatorname{Pr} \mathrm{T}$ & $\begin{array}{l}\operatorname{Pr} \mathrm{T} \\
\operatorname{Pr} \operatorname{Pr} A\end{array}$ & $\begin{array}{l}\text { Pr T } \\
\text { Pr Pr A } \\
\text { Pa T }\end{array}$ & & ' \\
\hline III . & $\begin{array}{l}\operatorname{Pr} T \\
\operatorname{Pr} \operatorname{Pr} A\end{array}$ & $\begin{array}{l}\operatorname{Pr} \mathrm{T} \\
\operatorname{Pr} \operatorname{Pr} \mathrm{A} \\
\operatorname{Pa} \mathrm{T} \\
\operatorname{Pa} \operatorname{Pr} \mathrm{A}\end{array}$ & $\begin{array}{l}\operatorname{Pr} T \\
\operatorname{Pr} \operatorname{Pr} A\end{array}$ & $\begin{array}{l}\operatorname{Pr} \mathbf{T} \\
\operatorname{Pr} \operatorname{Pr} A\end{array}$ & \\
\hline IV & $\mathbf{N}$ & $\mathbf{N}$ & $\mathbf{N}$ & & $\therefore$ \\
\hline V & & $\operatorname{Pr} T$ & $\operatorname{Pr} T$ & & \\
\hline VI & & $\mathbf{N}$ & $\operatorname{Pr} T$ & $\begin{array}{l}\operatorname{Pr} T \\
\operatorname{Pr} \operatorname{Pr} A\end{array}$ & \\
\hline VI1 & & $\mathbf{N}$ & $\begin{array}{l}\operatorname{Pr} T \\
\operatorname{Pr} \operatorname{Pr} A \\
\operatorname{Pa~T}\end{array}$ & $\begin{array}{l}\operatorname{Pr} T \\
\operatorname{Pr} \operatorname{Pr} A \\
\operatorname{Pa~T}\end{array}$ & $\begin{array}{l}\operatorname{Pr} \text { T } \\
\operatorname{Pr} \operatorname{Pr} \mathrm{A} \\
\operatorname{Pa} \cdot \mathrm{T} \\
\operatorname{Pa} \operatorname{Pr} \mathrm{A}\end{array}$ \\
\hline VIII & & $\mathbf{N}$ & $\operatorname{Pr} T$ & $\begin{array}{l}\text { Pr T } \\
\text { Pr Pr A }\end{array}$ & $\begin{array}{l}\operatorname{Pr} T \\
\operatorname{Pr} \operatorname{Pr} \mathrm{A} \\
\operatorname{Pa} \mathrm{T} \\
\operatorname{Pa} \operatorname{Pr} \mathrm{A}\end{array}$ \\
\hline IX & & $\mathbf{N}$ & $\operatorname{Pr} T$ & $\operatorname{Pr} T$ & $\begin{array}{l}+\operatorname{Pr} T \\
\operatorname{Pa} T\end{array}$ \\
\hline$X$ & & & $\begin{array}{l}\operatorname{Pr} T \\
\operatorname{Pr} \operatorname{Pr} A \\
\operatorname{Pa~} T\end{array}$ & $\begin{array}{l}\operatorname{Pr} T \\
\operatorname{Pr} \operatorname{Pr} A \\
\operatorname{Pa} T\end{array}$ & $\begin{array}{l}\operatorname{Pr} T \\
\operatorname{Pr} \operatorname{Pr} A \\
\operatorname{Pa} T \\
\operatorname{Pa} \operatorname{Pr} A\end{array}$ \\
\hline \multicolumn{6}{|c|}{$\begin{array}{l}\quad \text { Symbols: } \\
\text { No occurrence } \\
\text { Present Tense } \\
\text { Present Progressive Aspect } \\
\text { Past Tense (irregular Verb) } \\
\text { Past Progressive Aspect }\end{array}$} \\
\hline
\end{tabular}

Tydskrif van die Suid-Afrikaanse Logopediese Vereniging, Vol.17, Nr.1: Des. 1970 
time. The past tense verb inflection of irregular and regular verbs was used correctly by a much lower percentage.

The past tense of the irregular verb form was analysed because no evidence of the regular verb past tense inflection was found. It would require the allomorph $/$-ed $/$. In the training these hearing-impaired children received, they were exposed to all the verb tenses and inflections. Verb tenses or verb inflections were not taught per se, but whatever form seemed appropriate was used. In general they had more exposure to the past tense of both regular and irregular verbs than the other three forms described in this study.

The children used the following irregular verbs in the past tense: took, fell, were, had and got. These verbs were always inflected. When one looks at the acoustic dimension, the allomorph $/-t /$ that is required for the verbs used is a voiceless plosive and unstressed, and might be inaudible for the subjects: The irregular verb inflection requires a change in the vowel and might be available auditorily. The printed form of both regular and irregular verbs was presented to the children in their language training. Cazden (1968) reported that the irregular verb inflection is acquired by children first before the application of differential inflection rules ... irregular forms may start out as separate lexical items with no past meaning for the child. In spite of the fact that these children had been exposed to both forms of verb inflections, only one form was present in their spontaneous language utterances as transcribed by several listeners.

Verb plus Complement Construction: The verb plus complement construction was analysed because the picture stimulus seemed to elicit the use of transitive and intransitive verbs in the subject's spontaneous utterances. The structural description of a sentence with a verb plus complement is as follows:

Sentence: $\mathrm{S} \rightarrow \mathrm{NP}+\mathrm{VP}$

$$
\begin{aligned}
& \mathrm{NP}=\text { noun phrase } \\
& \mathrm{VP} \rightarrow \mathrm{V}+\mathrm{C}+(\mathrm{NP}) \\
& \mathrm{V}+\mathrm{C}=\text { verb }+ \text { complement } \\
& \mathrm{C}=\text { particle prepositional phrase }
\end{aligned}
$$

Two sentences can be formulated.

(a) Noun Phrase + Verb + Particle + Noun Phrase.

(b) Noun Phrase + Verb + Prepositional Phrase.

In adult grammar, sentence (b) with transitive verbs w would not be used and a transformation, Particle Displacement would have to apply. The structural change of the sentence representing the transformation is:

(c) Noun Phrase + Verb + Noun Phrase + Particle.

- The age and percentage of occurence of these three sentence constructions were determined. The percentage of children using the Verb + Complement construction suggests an increase of occurrence over years. At the eight and nine year level, it appeared in all the language samples and was used more frequently. The sentence structure, Noun Phrase + 
Verb + Prepositional Phrase occurred in all the language samples of children using the construction.

Omission of the preposition occurred only during the early language samples of individual children. Omission of prepositions appeared concurrently with the correct use of the preposition, followed soon by a stage of no omissions.

Menyuk (1964) reported that the child at the age of two years omits prepositions and uses them at two to six years of age, although not always where required. This stage is soon followed by correct application of prepositions.

The prepositions used by the ten children in this study were all of place and accompaniment. Menyuk (1964) found that the prepositional phrase of location is used before the prepositional phrase of time. Feofanov (1958), reporting on the use of prepositions in children's speech (ages three to seven), found that the earliest and most often used prepositions were those having the greatest number of meanings. The three most common prepositions were "in", "on" and "with". The earliest usages expressed primarily spatial relations. The use of prepositions expressing relations of purpose, time relations and space relations used figuratively, appeared later on.

The sentence structure, Noun Phrase + Verb + Particle + Noun Phrase which can be considered as a pre-transformational rule, was present in five language samples in the age range of seven to nine. The presence of this sentence structure may indicate that the children are using the same rule for particles with transitive and intransitive verbs.

$\begin{array}{lll}\text { Example: } & V+\text { Particle }+N P & V+\text { Prepositional Phrase } \\ & \text { take with the dishes } & \text { look at the dishes } \\ & \text { put on the pan } & \text { sit on the floor } \\ & \text { put up the pan } & \text { stand up }\end{array}$

The introduction of the transformation Particle Displacement would indicate an advanced stage of development in that the differentiation of treatment of particles with transitive and intransitive verbs is made. The developmental sequence could be exemplified as follows:

Subject $X$

$$
\begin{array}{cc}
\begin{array}{c}
\text { Stage I } \\
\text { Omission of Particle }
\end{array} & \begin{array}{c}
\text { Stage II } \\
\text { girl and boy put the pan }
\end{array} \\
\multicolumn{2}{c}{\begin{array}{l}
\text { Stage III } \\
\text { Transformation Particle Displacement }
\end{array}} \\
\text { he puts the pan on } \ldots \text { buts on the pan }
\end{array}
$$

\section{Transformation Particle Displacement}

Conjunction. The occurrence of conjunctions in the spontaneous language samples of this group of children indicates the usage of various rules. Different levels of complexity of the use of conjunctions were found as age increased.

The acquisition of conjunctions appears at an early age. The most frequently occurring conjunction was "and". Conjunctions "because" and "so" were used only by two subjects at age levels six and nine. To 
describe the development of the rules as they increase in complexity, an analysis of the rules found in the language samples was undertaken. The rules are as follows:

Rule 1. N + and + N (N: noun).

$$
\text { Adj }+ \text { and }+ \text { Adj. (Adj: Adjective). }
$$

Rule 2. NP + VP + and + NP + VP (NP: Noun Phrase) (VP: Verb Phrase).

Conditions: $1 \quad 2 \quad 3 \quad 4 \quad 5$

This is the conjunction of two kernel sentences in which all conditions are different, for example: The boy is laughing and the girl is crying

$1-2-3-4-5$

No condition in either kernel sentence can be deleted.

Rule 3. NP + VP + and + NP + VP

Conditions: $1 \quad 2 \quad 3 \quad 4 \quad 5$

Structurally rules 2 and 3 are the same, but in rule 3 certain conditions are identical. For example: The boy is laughing and the girl is laughing $1-2-3-4-5$

Conditions 2 and 5 are two verb phrases that are identical and condition 2 or 5 may therefore be deleted. Conjunction of the two kernel sentences in Rule 3 requires a transformation. The resulting transformation is Conjunction Deletion and is found in adult grammar. The use of Rule 3 in children's grammar may be considered as a development stage before the acquisition of the Conjunction Deletion transformation. Because the two rules are structurally the same, the child may apply this rule to all conjunctions of two kernel sentences before he acquires the differentiation between the two different and two identical conditions in sentences.

Rule 4. Conjunction Deletion No. 1.

In this transformation condition 2 as described above is deleted.

Rule 5. Conjunction Deletion No. 2.

Rule 5 also requires the deletion of conditions from one of two combined kernel sentences.

Structural Description:

$$
\begin{aligned}
& \mathrm{NP}+\mathrm{V}+\mathrm{NP}+\text { and }+\mathrm{NP}+\mathrm{V}+\mathrm{NP} \\
& \begin{array}{lllllll}
1 & 2 & 3 & 4 & 5 & 6 & 7
\end{array}
\end{aligned}
$$

the boy has socks and the boy has shoes

Structural Change: Transformation Conjunction Deletion No. 2.

$$
\begin{array}{ccccc}
\mathrm{NP} & \mathrm{VP} \\
1 & 2 & 3 & \mathrm{NP} & 4 \\
\hline
\end{array}
$$

the boy has shoes and socks

Condition 15 and 26 are identical and 5 and 6 must therefore be deleted to form the transformation Conjunction Deletion No. 2.

In the language development of these children there was a sharp decrease in the occurence of Rule 1, i.e. Noun+and+Noun. It oc- 
curred in the early language samples of the children who used it. The rule was either replaced by the conjunction kernel sentence + and + kernel sentence or used concurrently with the other rules. The use of the conjunction with two different kernel sentences increased rapidly and appeared as the dominant rule in all language samples at age levels seven, eight and nine. Rule 3 suggests a pre-transformation and would not appear in adult grammar. The use of Rule 3 occurred at early age levels, six and seven years. This pre-transformational rule was soon either replaced by the transformation Conjunction Deletion or used concurrently with the transformation.

Transformation Conjunction Deletion No. 1 occurred in the age range five to nine years. It was used by only one child at age five. There was a steady increase in the number of children using it and in the frequency of occurrence. The occurrence of the transformation was preceded by Rule 3 in the language samples of nine children. Transformation Conjunction Deletion No. 2 or Rule 5 occurred in the seven to nine year range. It was always used as a transformation. Two children at ages six and seven used the conjunction "and" to string many nouns together in a sentence. Example: the boy has some- and -sock and shoe and shoel-and pant and shoes and socks. This never occurred at the nine year level.

Menyuk (1963) reported on the development of transformations Conjunction and Conjunction Deletion by normal hearing children ranging in age from 3-0 to 6-0 years. Conjunction (e.g. Rule 2 in this study) was used by $87 \%$ of the children at age three; Conjunction Deletion was used by $62 \%$ of the children at age three. At ages five and six, Conjunction occurred in the language samples of all the children. Conjunction Deletion, however, was used less frequently but showed a steady increase in the number of children using it in the age range 3-8 to $6-0$ years. The transformation Conjunction is one of the few transformations used at the three year level.

Development of Syntax Structures. The comparison of the major sentence structures used most frequently at the various age levels indicated a developmental sequence similar to that of normal children. The use of kernel sentences increases as the children become older. The use of the kernel sentence alone as the underlying rule of all sentences in a language sample decreases rapidly. At the age of eight, it was always used with other transformations by all children. At the age of seven, only two out of eight children used the kernel sentence to formulate all their sentences. There appears to be a rapid increase in the use of transformations concurrently with the kernel sentences.

The transformation Auxiliary "have" occurred at age level seven with correct inflection in the language samples of all the children. It was not used frequently however. The transformation Pronoun occurred with high percentage and increased with age. Very few errors occurred. For each individual child, there was an increase in the different kinds of pronouns used. 
On the acquisition of the transformations Auxiliary "have" and Pronoun, Menyuk (1963) and Brannon (1967) reported a further development. The transformation Auxiliary "have" did not occur in the language of two and three year olds and appeared at age four or later. The transformation Pronoun was never used by three year olds and it seldom occurred at age four. The transformation Auxiliary "have" is based upon the use of specific word endings and seems to be a more difficult morphological form to acquire.

The presence of the transformation Comparative and Passive was also examined in the language samples of the ten subjects. The Comparative was used by three children at ages five, six and seven. It occurred only once in each language sample. The Passive was never used by any of the children.

The use of the Passive by normal hearing children as discussed by Menyuk (1964) suggested an increase in the number of children using it over the age range of 2-10 to 6-0 years. At 2-10 years it was used by one out of eight children; at ages $3-6$ to $3-9$ it was used by $48 \%$ of the children and by age six by $85 \%$.

At age levels eight and nine, the children were using kernel sentences as well as a greater number of different transformations, as compared with the sentences formulated at the earlier age levels. Of the six transformations examined, the Pronoun and Conjunction were the most frequently used and occurred at an earlier age. The introduction of more transformations in their language as this group became older indicates that they became less fixated as to the number of sentence types they were using in their spontaneous language utterances.

\section{Discussion}

The results from the analysis of the language samples suggests a developmental sequence of language acquisition by the ten hearing impaired children. The data will only allow the observation of developmental trends, since the number of children and language samples were small.

The language acquisition of the ten subjects appears to be similar to that of normal hearing children. The main difference is the chronological age at which the grammatical structures emerged. The usage of verb tenses and verb forms indicated similarity with normal hearing children as described by Cazden (1968) and Berko (1966). The áppearance of the kernel sentence demonstrated the children's early sýntactic development. The kernel sentence appeared after single word and two or three word combinations for some children. Other children were already at the stage of using kernel sentences when their language was first recorded.

The major portion of syntactic acquisition for normal children after kernel sentences is the growth of transformations. The ten subjects used transformations more frequently as they became older. The transformation Conjunction was one of the earliest acquired transformations. 
Similar results were reported by Menyuk (1964). The appearance of Conjunction Deletion No. 1 was preceded by a pre-transformational construct. This appears to demonstrate a developmental stage in the formulation of rules by the children.

The development of transformation Particle Displacement was preceded by the application of a generalized rule to combine verbs and particles. At a later age, a rule to.differentiate between transitive and intransitive verbs with particles appeared. In the school situation, the transformation Particle Displacement would have been incorporated. There appears to be indication of development from generalizing rules to correct application of the transformation.

The transformation Auxiliary "have" is acquired by normal children at age three or later. The hearing impaired children used it infrequently, and it appeared later than transformations Conjunctions and Pronoun.

The prepositions that occurred in the hearing impaired children's spontaneous language were those of place and accompaniment. According to Feofanov (1958), they are the first prepositions acquired by normal hearing children.

The language acquisition of these children does reflect rote performances or memorized strings of words. These data lend support to the hypothesis that deaf children, as well as normal hearing children, have an innate capacitiy for language acquisition. Lennenberg (1964) stated that: "Deaf children could hardly differ in the capacity for doing this, from hearing children, provided they were given enough examples and are allowed to go through a natural order of grammatical development. This capacity to acquire language can be demonstrated by the rules and/or categorization of rules used to formulate sentences. The hearing impaired child is limited in his ability to test hypotheses against adult speech, and language exposure and instruction is brought to the task of language acquisition. A training programme utilizing the theory of the innate capacity would necessitate the provision of many language constructs so that the deaf child would be given the opportunity of inducing the structural principles of the language in a natural way. The capacity to acquire language appears to be transitory (McNeill 1966). This suggests that concentrated language exposure and teaching should begin early, i.e. before the age of four, which is the age at which some investigators have said the child is at his peak of language acquisition.

\section{Summary}

Spoken samples of language from a group of ten hearing impaired children were analysed with respect to development of occurrence of verb tenses and verb inflections, the development of the kernel sentence and four transformations: conjunction, particle displacement, auxiliary "have" and pronoun. The language samples represented an age range of five-three to nine-seven years. The mean hearing level of the ten subjects, in the better ear was $76 \mathrm{~dB}$ I.S.O. 
From the results obtained, general conclusions seem to emerge. Firstly, the earliest acquired verb tense is the present, followed by, or appearing concurrently with, the present progressive. Secondly, the kernel sentence is correctly used at an early age by some children. As age increases, so does the percentage of children using the kernel sentence. From approximately seven years of age, more transformations are used. The transformations conjunction and particle displacement indicated a clear developmental trend towards greatér complexity. The conjunction and pronoun transformations were used by a greater percentage of children. The transformation auxiliary "have" appeared much later and less frequently.

These developmental trends show strong similarities to the trends observed in normal hearing children by other investigators. There is, however, a time lag in that the hearing impaired children develop these features at a later age and over a longer period of time.

\section{Opsomming}

Spontane spraakvoorbeelde van 'n groep van tien gehoorgestremde kinders is ontleed met verwysing na die ontwikkeling van die voorkoms van werkwoordtye en verbuigings, die ontwikkeling van die kernsin en vier transformasies. Die taalvoorbeelde verteenwoordig 'n ouderdoms omvang van vyf-drie tot nege-sewe jaar. Die gemiddelde gehoorpeil van die tien proefpersone, in die beter oor, was 76dB I.S.O.

Sekere ontwikkelingsneigings is gevind in die taal van die kinders wat ooreenkomste getoon het soos gevind deur ander ondersoekers by normale kinders. Daar is egter 'n tydsverskil, in die dat die gehoorgestremde kinders die taalelemente op 'n later ouderdom en oor 'n langer periode van tyd ontwikkel het.

\section{Bibliography}

1. Berko, J., The child's learning of English morphology. Psycholinguistics, Ed. S. Saporta, 1966.

2. Brown, R., Bellugi, U., Three processes in the child's acquisition of syntax. Harvard Educ. Rev., 1964, 34, 133-151.

3. Brown, R., Frazer, C., The acquisition of syntax. Mon. Soc. Rescarch in Child Development, 1964, 29, 43-78.

4. Cazden, C. B., The acquisition of noun and verb inflections. Child Development, 1968, 39, 433-448.

5. Chomsky, N., Aspects of the theory of syntax. M.I.T. Press, 1965.

6. Feofanov, M. P., On the use of prepositions in child speech. Genesis of language, M.I.T. Press, 1966, 366-367.

7. Fries, C. C., The structure of English: An introduction to the construction of English sentences, New York, 1952.

8. Goda, S., Spoken syntax of normal, deaf and retarded adolescents. Journal of Verbal Learning and Verbal Behavior, 1964, 3, 401-405.

9. Lennenberg, E. H., Biological foundations of language. Wiley, New York, 1967.

10. MacGinitic, W., Ability of deaf children to use different word classes. J.S.H.R., 1964, 7, 141-150.

Journal of the South African Logopedic Society, Vol. 17, No. 1: December 1970 
11. McNeill, D., The capacity of language acquisition. Volta Review, 1966, 39, 17-32.

12. Menyuk, P., Alteration of rules in children's grammar. Journal of Verbal Learning and Verbal Behavior, 1964, 3, 480-488.

13. - Syntactic rules used by children from preschool through first grade. J Child Development, 1964, 533-546.

14. - Comparison of grammar of children with functionally deviant and normal speech. J.S.H.R., 1964, 7, 109-121.

15. Miller, W., Ervin, S., The development of child grammar in child language. Mon. Soc. Res. Child Development, 1964, 29. 